\title{
Effect of an Educational Program on Nurses' knowledge \&Practices Regarding Assessment of Acute Coronary Syndrome
}

\author{
Suzan Ahmed Fares ${ }^{1}$, Mohamed Hosam EL-Din Maghraby ${ }^{2}$, Olfet Abd AL-Ghany EL-shafiey ${ }^{3}$ \& Mogedda \\ Mohamed Mehany ${ }^{4}$. \\ 1- Nursing Specialist in Manfalout's Reproductive Health Hospital, Egypt. \\ 2- Professor of Medical diseases department, Faculty of Medicine, Assuit University, Egypt. \\ 3- Assistant Professor of Critical Care Nursing, Faculty of Nursing-Assiut University, Egypt. \\ 4- Assistant Professor of Critical Care Nursing, Faculty of Nursing-Assiut University, Egypt.
}

\begin{abstract}
Background: Acute coronary syndrome (ACS) refers to a group of conditions due to decreased blood flow in the coronary arteries such that part of the heart muscle is unable to function properly or dies. Aim: To evaluate the effect of implementing an educational program on knowledge and practices of critical care nurses regarding acute coronary syndrome. Sampling: convenient samples of 30 nurses recruited from coronary and Emergency care unit at Manfalout's Reproductive Health Hospital. Research design: quasi-experimental research design (one-group pretest-posttest design) was used for implementation this study. Result: Most of nurses (66.7\%) had unsatisfactory level of knowledge regarding acute coronary syndrome, Most of nurses $(36.7 \%)$ had unsatisfactory level of practice regarding acute coronary syndrome and no significant statistical relation between knowledge and practice level of studied nurses. Data collection: Data were collected in six months. Conclusion: empowerment of emergency nurses' knowledge and practices would have a positive impact upon their knowledge and practice related to acute coronary syndrome. Recommendations: All nurses should be equipped with the necessary knowledge and practice regarding acute coronary syndrome.
\end{abstract}

\section{Keywords: Acute Coronary Syndrome, Educational Program, Knowledge \& Practice.}

\section{Introduction}

Cardiovascular disease (CVD) is a number one cause of death globally for both men and women and is projected to remain the leading cause of death ,unstable angina and non-st - elevation acute coronary syndrome (NSTE-ACS)are responsible for approximately5.3million emergency department visits and 1.4million hospitalization per year. (Nichols, et al., 2014).

Acute coronary syndrome (ACS) happens when the heart is not getting enough blood, it is an emergency it includes unstable angina and heart attack. Coronary arteries supply oxygen-rich blood to the heart muscles. If the heart does not get enough oxygen this can cause angina or heart attack. The most common symptom is chest pain, often radiating to the left arm or angle of the jaw, pressure-like in character, and associated with nausea and sweating. Acute coronary syndrome usually occurs as a result of one of three problems: ST elevation myocardial infarction (30\%), non ST elevation myocardial infarction (25\%), or unstable angina (38\%) . (Amsterdam, et al., 2014). Chest pain may be a sign of a life threatening medical emergency, or it may be an uncomfortable symptom of a passing problem, like a pulled muscle or indigestion. Chest pain is pain experienced anywhere from the neck to the upper abdomen. It may be experienced as dull, aching, burning, stabbing, tight, or sharp. One might think chest pain indicates a heart problem, but that is not always the case. Pain coming from the lungs, esophagus, or ribs may all be described as chest pain. These are a few of the reasons may be experiencing chest pain some serious, some not. (Skiner, et al., 2014).

The cardiovascular nursing assessment and health history provide physiological and psychosocial information that guides the physical assessment, the selection of diagnostic test, and the choice of treatment options .during the history, the nurse asks about the patient's chief complaint and the history of the present illness, including a complete analysis of each signs and symptom and nurse asks about the patient' $s$ past health history, family history , personal and social history and to evaluate the patient's general and emotional status. (Patricia \& Dorrie, 2013).

Cardiac chest pain and non-cardiac chest pain (NCCP) can both appear behind breastbone, making it hard to distinguish between the two types of pain. Cardiac chest pain is more likely than reflux-related pain to spread to other parts of body. These places include Arms, especially the upper part of left arm, Back, Shoulders and Neck (Bryant \& Knights, 2010). 


\section{Significance of the study}

Acute coronary syndrome (unstable angina, myocardial infarction, sudden cardiac death) is the major causes of morbidity and mortality in developed countries, MI alone is the major causes of death in most western countries the rapidly increase prevalence in developing countries, specifically South Asia and Eastern Europe with an increasing incidence of tobacco abuse, obesity, and diabetes is predicted to make cardiovascular disease the make cardiovascular disease the major global causes of death by 2020.(Jeremias, et al., 2010), Statistical of Egyptian coronary care unit at Manfalout's Hospital in year of (2015) revealed that the number of patient admitted with ACS were (224) patient (Manfalout's Hospital Record, 2015).

\section{Aim of the study}

To evaluate the effect of implementing an educational program on knowledge and practices of critical care nurses regarding acute coronary syndrome.

\section{Material and Method \\ Study design}

quasi- experimental research design with one group pre-test post-test was used in this study

\section{Study hypothesis}

Educational program regarding assessment of acute coronary syndrome improve both knowledge and practice of the nurses working in coronary care unit at Manfalout's Reproductive Health Hospital.

\section{Study variables}

- independent variable is the educational program.

- dependent variables are the nurse 'knowledge and practices.

\section{Setting}

This study was conducted in coronary care unit in Manfalout's Reproductive Health Hospital.

\section{Sampling}

A convenience sample of all nurses (30) working in coronary care unit, Emergency unit.

\section{Tool of the study}

Two tools were used in this study

\section{Part I}

questionnaire assessment tool; this tool was developed by researcher after literature reviewing to assess the knowledge level of coronary care nurses regarding assessment of acute coronary syndrome which include two sections:

Nurses' demographic data: demographic characteristics of the nurses as age, sex, marital status, qualification, and years of experience and attendance of previous training program in ACS.

Nurses' knowledge data: questions regard definition, causes, signs\& symptoms, assessment of chest Pain, Site of chest pain, Factor effecting of chest pain, risk factors of acute coronary syndrome, complication of acute coronary syndrome and how to prevent of heart disease and blood vessels, nurse's response were checked with model answer and given points; these points were summed up and converted into percent score. A total score less than $60 \%$ was considering poor unsatisfactory level of knowledge). While $60 \%$ or more from total score was considered as satisfactory level of knowledge which subgroup into (60-64\% fair, $65-74 \%$ good, $75-84 \%$ very good, $85 \%$ or more was consider excellent.

\section{Part II}

Practice assessment tool: the nursing practice observational checklist this tool was developed by the researcher after reviewing pertinent literature to assess the performance level of critical care nurses regarding assessment of acute coronary syndrome which include (ECG, Cardiac monitoring, and oxygen therapy). The observed practice was compared with stander procedures. Accordingly nurses had one mark if the step was correctly and zero if incorrectly done or not done, the marks was assumed up and converted into percent score. A total score less than $60 \%$ was considering poor (unsatisfactory level of practice). While $60 \%$ or more from total score was considered as satisfactory level of practice which subgroup into $(60-64 \%$ fair, 65$74 \%$ good, $75-84 \%$ very good, $85 \%$ or more was consider excellent.

\section{Ethical considerations}

An official permission to conduct the study was obtained from the hospital responsible authorities in CCU after explaining the aim and nature of the study. An approval was obtained from the local ethical committee and the study was followed the common ethical principles in clinical research. The tools used in this study were developed by the researcher based on reviewing the relevant literature.

\section{Validity of tools}

The tools were tested for content validity by jury of 5 experts in the field of critical care nursing and necessary modification was done.

\section{Pilot study}

Was conducted on 5 nurses to test the feasibility and applicability ( included).

Reliability:

Was test for tool one (knowledge assessment tool).and tool two (skill assessment tool) by using 
cronbach,s coefficient alpha $(\mathrm{r}=0.815, \quad 0.795$ respectively).

The study was implemented through 4 phases Assessment: upon finalization of the tools and getting official permission the researcher stated to assess nurse knowledge by using self-administered questionnaire sheet, this was followed by observing their practice in different shift using the observational checklist by (Participant observation, structured observation and field observation)

Planning: based on analysis of the collected data and using pertinent literature the researcher was developed an educational program in form of hand out booklet in Arabic language. The objective of program was improving nurses 'knowledge and practice regarding emergency care of patients with acute coronary syndrome. The program was developed to cover all necessary knowledge and practice needed for proper practice.

Implementation: implementation of educational program took four weeks. The program was applied for all nurses working in emergency care unit and CCU. It not applicable for all nurses attends an educational session at the same time, so they were divided into groups 3-5 according to their work schedule

\section{Educational program objectives are based on}

General objective; the goal of the program is to help nurses develop knowledge and practice

Specific objective ; the program is help nurses able to identify of anatomy and physiology of the heart, Definition, causes, sings \& symptoms of acute coronary syndrome and chest Pain assessment

The program covers 2 parts

Theoretical part: which include

a) First session last for $(15 \mathrm{~min})$.include

Anatomy and physiology of the heart, Short note about acute coronary syndrome in general

b) Second session last for $(30 \mathrm{~min})$ which includes

Definition, causes, sings \& symptoms \& emergency nursing care of acute coronary syndrome.

c) Third session last for $(30 \mathrm{~min})$ which includes Assessment of vital signs which includes (temperature, reparation, plus and blood pressure).

Chest Pain assessment: this is indicator of presence of chest pain using (NOPQRST) that includes (Normal, Onset, Precipitating and Palliative factors, Quality and Quantity (visual assessment), Region and radiation, Severity, and Time).

d) Forth session last for (30 min) which includes Cardiac assessment requires examination of all aspects of individual using (inspection, palpation, percussion (some patients may present with symptoms other than chest comfort; such "angina equivalent" symptoms include dyspnea (most common), nausea and vomiting and syncope may be the presenting symptom of ACS, and auscultation).

Practice part includes

ECG, Oxygen therapy and cardiac monitoring.

Learning environment

The program was applied in a classroom of the coronary care unit .

\section{Teaching methods}

Lectures, brain storming, discussion, demonstration (learning by seeing and doing), and re-demonstration.

Media used

Power point, Handout, poster, and demonstration equipment.

Observation checklist: Was assessed by the research before and after training program implementation, it was assessed which skills of each nurse, practical contents were constructed based on the observation checklist results, the observation checklist including: oxygen therapy, cardiac monitoring, and electrocardiogram and nursing evaluating.

Evaluation phase: each nurse was evaluated twice time before (pretest), and after the program implementation (posttest) and these were compare to pre-test level by using the same pre-test study tools (knowledge sheet and observational checklist).

\section{Setting:-}

This study was conducted in coronary care unit class in Manfalout's Reproductive Health Hospital.

Statistical analysis of the data

The collected data were coded and entered in a data based file using the excel program for windows frequency analysis and manual revision were used to detect any errors. Statistical analysis was performed using software program package SPSS, version 13. Values are expressed as mean+-standard deviation or percentages of the group from which they were derived. Independent sample t-test was used to compare the values of the mean score between the study groups. The critical value of the tests (p) was considered statistically significant when $\mathrm{P}$ less than 0.05 . 
Results

Table (1): socio demographic characteristics of the studied sample $($ No $=30)$.

\begin{tabular}{|c|c|c|}
\hline Item & No. $(n=30)$ & $\%$ \\
\hline \multicolumn{3}{|l|}{ Age: (years) } \\
\hline$<30$ & 11 & 36.7 \\
\hline $30-35$ & 7 & 23.3 \\
\hline$>35$ & 12 & 40.0 \\
\hline Mean \pm SD (Range) & \multicolumn{2}{|c|}{$32.70 \pm 5.46(24.0-40.0)$} \\
\hline \multicolumn{3}{|l|}{ Sex: } \\
\hline Female & 30 & 100.0 \\
\hline \multicolumn{3}{|l|}{ Years of experience: } \\
\hline$<5$ & 4 & 13.3 \\
\hline $5-10$ & 6 & 20.0 \\
\hline$>10$ & 20 & 66.7 \\
\hline \multicolumn{3}{|l|}{ Marital status: } \\
\hline Married & 27 & 90.0 \\
\hline Single & 3 & 10.0 \\
\hline \multicolumn{3}{|l|}{ Qualification: } \\
\hline Technical Institute of Nursing & 5 & 16.7 \\
\hline Secondary School of Nursing & 25 & 83.3 \\
\hline \multicolumn{3}{|c|}{$\begin{array}{l}\text { Attending training courses about nursing care for patients } \\
\text { with acute coronary syndrome: }\end{array}$} \\
\hline Yes & 5 & 16.7 \\
\hline No & 25 & 83.3 \\
\hline \multicolumn{3}{|l|}{ No. of training courses: } \\
\hline Two & 3 & 60.0 \\
\hline Three or more & 2 & 40.0 \\
\hline
\end{tabular}

Table (2): Mean distribution of Nurses 'knowledge before and after Implementation educational program regarding assessment of acute coronary syndrome.

\begin{tabular}{|c|c|c|c|c|c|}
\hline \multirow[t]{2}{*}{ Item } & \multicolumn{2}{|c|}{$\begin{array}{c}\text { Before } \\
\text { implementation } \\
(\mathbf{n}=\mathbf{3 0})\end{array}$} & \multicolumn{2}{|c|}{$\begin{array}{c}\text { Before } \\
\text { implementation } \\
(n=30)\end{array}$} & \multirow[t]{2}{*}{ P-value } \\
\hline & No. & $\%$ & No. & $\%$ & \\
\hline \multicolumn{5}{|c|}{ Anatomy \& physiology of the heart } & \multirow{3}{*}{$0.005^{*}$} \\
\hline Incorrect & 8 & 26.7 & 0 & 0.0 & \\
\hline Correct & 22 & 73.3 & 30 & 100.0 & \\
\hline \multicolumn{5}{|l|}{ Definition of ACS } & \multirow{3}{*}{$0.000 *$} \\
\hline Incorrect & 21 & 70.0 & 0 & 0.0 & \\
\hline Correct & 9 & 30.0 & 30 & 100.0 & \\
\hline \multicolumn{5}{|l|}{ Signs and symptoms of ACS } & \multirow{3}{*}{$0.000^{*}$} \\
\hline Incorrect & 22 & 73.3 & 2 & 6.7 & \\
\hline Correct & 8 & 26.7 & 28 & 93.3 & \\
\hline \multicolumn{5}{|l|}{ Risk factors of ACS } & \multirow{3}{*}{$0.000^{*}$} \\
\hline Incorrect & 23 & 76.7 & 0 & 0.0 & \\
\hline Correct & 7 & 23.3 & 30 & 100.0 & \\
\hline \multicolumn{5}{|l|}{ Assessment of chest pain } & \multirow{3}{*}{$0.007 *$} \\
\hline Incorrect & 16 & 53.3 & 6 & 20.0 & \\
\hline Correct & 14 & 46.7 & 24 & 80.0 & \\
\hline
\end{tabular}




\begin{tabular}{|c|c|c|c|c|c|}
\hline \multirow[t]{2}{*}{ Item } & \multicolumn{2}{|c|}{$\begin{array}{c}\text { Before } \\
\text { implementation } \\
(n=30)\end{array}$} & \multicolumn{2}{|c|}{$\begin{array}{c}\text { Before } \\
\text { implementation } \\
(n=30)\end{array}$} & \multirow[t]{2}{*}{ P-value } \\
\hline & No. & $\%$ & No. & $\%$ & \\
\hline \multicolumn{5}{|l|}{ Causes of chest pain } & \multirow{3}{*}{--} \\
\hline Incorrect & 0 & 0.0 & 0 & 0.0 & \\
\hline Correct & 30 & 100.0 & 30 & 100.0 & \\
\hline \multicolumn{5}{|l|}{ Complication of ACS } & \multirow{3}{*}{$0.000 *$} \\
\hline Incorrect & 20 & 66.7 & 1 & 3.3 & \\
\hline Correct & 10 & 33.3 & 29 & 96.7 & \\
\hline \multicolumn{5}{|c|}{ Prevention of cardiovascular disease } & \multirow{3}{*}{1.000} \\
\hline Incorrect & 2 & 6.7 & 2 & 6.7 & \\
\hline Correct & 28 & 93.3 & 28 & 93.3 & \\
\hline
\end{tabular}

Table (3): Mean \pm SD distribution of nurses 'practice score before $\&$ after implementation the educational program regarding assessment of ACS.

\begin{tabular}{|c|c|c|c|}
\hline \multirow[t]{2}{*}{ Performance item } & $\begin{array}{c}\text { Before } \\
\text { implementation } \\
(\mathbf{n}=\mathbf{3 0})\end{array}$ & $\begin{array}{c}\text { Before } \\
\text { implementation } \\
(\mathbf{n}=\mathbf{3 0})\end{array}$ & \multirow[t]{2}{*}{ P-value } \\
\hline & Mean \pm SD & Mean \pm SD & \\
\hline Oxygen Therapy & $15.47 \pm 2.65$ & $31.37 \pm 2.95$ & $0.000 *$ \\
\hline ECG & $46.77 \pm 2.54$ & $48.90 \pm 1.83$ & $0.000 *$ \\
\hline cardiac monitor & $27.37 \pm 6.18$ & $49.20 \pm 4.92$ & $0.000 *$ \\
\hline Total score & $89.60 \pm 7.07$ & $129.47 \pm 6.29$ & $0.000 *$ \\
\hline
\end{tabular}

Table (4): Relation between Socio demographic data $\&$ nurses 'knowledge (before $\&$ after implementation the educational program).

\begin{tabular}{|c|c|c|c|c|}
\hline \multirow{3}{*}{ Items } & \multicolumn{4}{|c|}{ Score of knowledge } \\
\hline & \multirow{2}{*}{\begin{tabular}{|c|}
$\begin{array}{c}\text { Before } \\
\text { implementation }\end{array}$ \\
Mean \pm SD \\
\end{tabular}} & \multirow[t]{2}{*}{ P-value } & $\begin{array}{c}\text { Before } \\
\text { implementation }\end{array}$ & \multirow[t]{2}{*}{ P-value } \\
\hline & & & Mean \pm SD & \\
\hline \multicolumn{2}{|l|}{ Age: (years) } & \multirow{4}{*}{0.393} & & \multirow{4}{*}{0.496} \\
\hline$<30$ & $30.27 \pm 6.80$ & & $44.18 \pm 4.38$ & \\
\hline $30-35$ & $28.00 \pm 7.23$ & & $45.71 \pm 3.35$ & \\
\hline$>35$ & $27.42 \pm 5.25$ & & $46.58 \pm 3.12$ & \\
\hline \multicolumn{2}{|l|}{ Years of experience: } & \multirow{4}{*}{$0.007 *$} & & \multirow{4}{*}{0.562} \\
\hline$<5$ & $36.25 \pm 2.06$ & & $44.25 \pm 4.35$ & \\
\hline $5-10$ & $30.50 \pm 3.67$ & & $45.67 \pm 5.39$ & \\
\hline$>10$ & $26.50 \pm 6.09$ & & $45.70 \pm 3.16$ & \\
\hline \multicolumn{2}{|l|}{ Marital status: } & \multirow{3}{*}{0.445} & & \multirow{3}{*}{0.650} \\
\hline Married & $28.30 \pm 6.39$ & & $45.78 \pm 3.29$ & \\
\hline Single & $31.33 \pm 4.62$ & & $43.00 \pm 7.00$ & \\
\hline \multicolumn{2}{|l|}{ Qualification: } & \multirow{3}{*}{$0.018 *$} & & \multirow{3}{*}{0.911} \\
\hline Technical Institute of Nursing & $34.20 \pm 4.92$ & & $45.00 \pm 4.12$ & \\
\hline Secondary School of Nursing & $27.48 \pm 5.93$ & & $45.60 \pm 3.71$ & \\
\hline \multicolumn{2}{|l|}{$\begin{array}{l}\text { Attending training courses about nursing } \\
\text { care for patients with acute coronary } \\
\text { syndrome: }\end{array}$} & \multirow[t]{3}{*}{$0.027 *$} & & \multirow[t]{3}{*}{0.955} \\
\hline Yes & $34.00 \pm 5.34$ & & $45.40 \pm 4.56$ & \\
\hline No & $27.52 \pm 5.92$ & & $45.52 \pm 3.63$ & \\
\hline
\end{tabular}


Table (5): Relation between Socio demographic data \& Nurses 'practice (before\& after implementation the educational program).

\begin{tabular}{|c|c|c|c|c|}
\hline \multirow{3}{*}{ Items } & \multicolumn{4}{|c|}{ Score of performance } \\
\hline & $\begin{array}{c}\text { Before } \\
\text { implementation }\end{array}$ & \multirow[t]{2}{*}{ P-value } & $\begin{array}{c}\text { After } \\
\text { implementation }\end{array}$ & \multirow[t]{2}{*}{ P-value } \\
\hline & Mean \pm SD & & Mean \pm SD & \\
\hline Age: (years) & & \multirow{4}{*}{0.181} & & \multirow{4}{*}{0.179} \\
\hline$<30$ & $88.36 \pm 4.25$ & & $130.55 \pm 7.38$ & \\
\hline $30-35$ & $94.29 \pm 8.69$ & & $128.71 \pm 9.39$ & \\
\hline$>35$ & $88.00 \pm 7.47$ & & $128.92 \pm 2.19$ & \\
\hline Years of experience: & & \multirow{4}{*}{0.993} & & \multirow{4}{*}{0.276} \\
\hline$<5$ & $90.00 \pm 6.06$ & & $133.50 \pm 7.05$ & \\
\hline $5-10$ & $89.00 \pm 3.79$ & & $128.67 \pm 8.45$ & \\
\hline$>10$ & $89.70 \pm 8.16$ & & $128.90 \pm 5.46$ & \\
\hline Marital status: & & \multirow{3}{*}{0.556} & & \multirow{3}{*}{0.862} \\
\hline Married & $89.59 \pm 7.45$ & & $129.44 \pm 6.39$ & \\
\hline Single & $89.67 \pm 1.53$ & & $129.67 \pm 6.51$ & \\
\hline Qualification: & & \multirow{3}{*}{0.596} & & \multirow{3}{*}{0.139} \\
\hline Technical Institute of Nursing & $90.40 \pm 5.13$ & & $133.40 \pm 6.80$ & \\
\hline Secondary School of Nursing & $89.44 \pm 7.47$ & & $128.68 \pm 6.02$ & \\
\hline $\begin{array}{l}\text { Attending training courses about nursing } \\
\text { care for patients with acute coronary } \\
\text { syndrome: }\end{array}$ & & \multirow[t]{3}{*}{0.403} & & \multirow[t]{3}{*}{0.124} \\
\hline Yes & $92.40 \pm 7.50$ & & $133.00 \pm 6.20$ & \\
\hline No & $89.04 \pm 7.00$ & & $128.76 \pm 6.19$ & \\
\hline
\end{tabular}

Table (6): Correlation between Total score of Nurses 'knowledge and Practice Scale.

\begin{tabular}{|l|c|c|}
\hline \multicolumn{1}{|c|}{ Groups } & r-value & P-value \\
\hline Before implementation & -0.058 & 0.762 \\
\hline After implementation & 0.058 & 0.761 \\
\hline
\end{tabular}

Table (1): Shows socio demographic characteristics of the studied nurses, it observed that the majority of studied nurses $(40 \%)$ were at the age group $>35$ years with a mean age $32.70+5.46$, Majority of nurses are Married(90\%), the years of experiences of studied nurses less than 5 years were(13.3), the majority of studied nurses work as bed side nurses, graduated from Technical Institute of Nursing $(16.7 \%) \&$ more than half of the studied nurses had diploma Secondary School of Nursing $(83.3 \%)$

Table (2): Show that total mean score nurses 'knowledge score of assessment of acute coronary syndrome of nurses were with Mean $28.60 \pm 6.24$ in pre-test ,total knowledge score of assessment of acute coronary syndrome $(45.50 \pm 3.7145 .50 \pm 3.71)$ in post-test.

Table (3): Show the statistical significant difference between nurses 'practice indicating good practices after educational program, compared withpoor practice before educational program regarding assessment of ACS.

Table (4): Show no significant relation between nurses 'knowledge score and Socio- demographic data before and after implementation the educational program.

Table (5): Show no significant relation between nurses 'practice score and Socio- demographic data pre and post conducting the educational program.

Table (6): Show no significant statistical relation between nurses 'knowledge score and nurses 'practice before and after implementation the educational program.

\section{Discussion}

Cardiovascular disease is the highest-incidence cause of death and morbidity in the general population. Acute coronary syndrome (ACS) is a complex syndrome with heterogeneous etiology. New biomarkers that reflect the diverse path biology of 
acute ischemic heart disease have emerged and are being investigated for use as noninvasive means to gain insight into the underlying causes and consequences of ACS. (Battistoni, et al., 2012).

Acute coronary syndrome refers to a range of potentially life-threatening conditions that affect the coronary artery blood supply to the heart, and is a common presentation in patients with coronary heart disease. Understanding the diagnostic approaches, as well as pharmacological and coronary interventions is crucial, given the prevalence of ACS. (Jarvis \& Saman, 2017).

The present study revealed the total score of nurses' knowledge and practice of the nurses before implementation of the educational program, was poor scores regarding total items of assessment of ACS, this may be due to they had not receive previous training program about assessment of ACS ,there is not updating for knowledge received during undergraduate and there is no motivation from the administration, no pre-employment orientation program, insufficient number of nurses, inadequate salary and lack of instructions.

The result similar to the result revealed by ( Abd ELnaeem, 2015) who stated that the majority of the studied nurse, generally was poor level of knowledge and practice before implementation of an educational program, due to no pre-employment orientation, deficiencies in training courses, increased work load which may hinder the ability to read and update their knowledge .

The result also, showed that the majority of nurses didn't receive training program about assessment of ACS. This was similar to result revealed by (AlJanabi\& Al- Ani, 2014) they concluded that the most of the sample didn't have any formal training courses.

This result was in line with (Ali, 2011) who mentioned that lack of nurse's information about disease nature, causes, S\&S, and management may lead to increased incidence of complications.

That study show, there were statistically significant improvement in nursing staff knowledge and practice after implementation of an educational program, this because the educational program was effective and they were need to an educational program.

This result agrees with (Revit, 2012) who stated that after the educational module, there significant improvement in knowledge scores of nurse (ALshonee, 2014) figured out that, there was significant improvement in nursing staff knowledge and practice after the application of the training program.

The nursing staff is need for continuous training and applying this training to improve the stander of patient care, the educational program is considered to be important means to provide nurses with theoretical and technical information need to acquired skills and competencies necessary to continually improve nursing practice. It helps them to accept responsibility for their development. The educational program is designed to assist health worker to maintain and improve their competencies and acquire new knowledge (Barbara, 2012).

There was no statistical significant difference relation between socio-demographic characteristic \&total score of knowledge and practice (before and after implementation of educational program). These result may be due to the studied group were heterogonous group, the majority of them nearly at the same year of experience, The nurses improve their practices by experience in the field of work

This result agree with(Abd El-neam , 2015) who found that there were no significant difference between knowledge and gender, year of experience and educational level, it indicate that ere was no effect of gender, year of experience and educational level on teaching program regarding knowledge. But this study mentioned also that there was a significant positive correlation nurses' knowledge and nurses' age.

The result was disagree with (Christofer, 2007) who found that there were positive correlation between knowledge and age. On the same line (Taha, 2012) showed a positive correlation between knowledge and practice and age.

There was no statistical significant correlation between nurses 'knowledge and practice before and after implementation the educational program.

In my opinion, the nurse should be having knowledge before practice.

This agrees with (Taha, 2012) who illustrated that nurses should attain and maintain a high level of nursing knowledge and nursing practice to be effective in practice. This also with (Musleh, 2015) who found that there was a high statistic differences pre and post educational program with knowledge and practice level. This finding was disagree with (Cui \& Lil , 2013) who found that conducted a study about knowledge and practice of critical care nurses and conducted a statistical significant relationship between knowledge and practice level.

\section{Conclusion}

Based on the results of the present study

- A statistical significant improvement was found between the nurses ' level of knowledge before and after implementation of an educational program regarding assessment of acute coronary syndrome. 
- A statistical significant improvement was found between the nurses ' level of skill before, and after implementation of an educational program regarding assessment of acute coronary syndrome

\section{Recommendations}

Based on the results of the present study, it can be recommended that

- All nurses should be equipped with the necessary knowledge and practice regarding cardiovascular disease in ICU (learning by seeing and doing).

- Orientation program should be utilized for newly graduated nurses to improve their knowledge and practice along with continuous super vision.

- The guide lines booklet of cardiovascular disease should be available in written formation in critical care units and emergency units.

\section{Reference}

1. Abd - ELneam M., (2015): Effect of implementing cardiopulmonary resuscitation teaching program on knowledge\& skill of critical care nursing, Doctorate degree critical , critical Nursing, faculty of Nursing ,Assuit University, discussion part 90

2. AL-Janabi M., AL-Ani B., (2014): Assessment of nurses 'knowledge toward cardio pulmonary resuscitation at AL-Nagaf City's, Teaching Hospital, Journal of Kufa for nursing science, $\operatorname{vol}(4), \operatorname{No}(1)$

3. ALshonee, (2014): Assessment of nurses 'knowledge and performance related to infection control precautions at mallawy General Hospital Departments, pp(93-97).

4. Ali Z., (2011): Health and knowledge progress among Diabetic patients after implementation of nursing care program based on their profile, $\mathrm{J}$ diabetic Me tab, 2:121.

5. Amsterdam E., Wenger N., Brindis R., Jenid H., (2014): AHA/ACC Guideline for management of patients with Non-ST-Elevation Acute Coronary Syndrome: A Report of American College of Cardiology /American Heart Association Task force on practice guideline, ed(130), vol(25),pp344-425

6. Barbara A., (2012): acls study guide $4^{\text {th }}$ edition, Mosby, an imprint of ELsevvier Inc. printed in the USA 9-23,30-35,"62'

7. Battisoni A., Rubattu S., Volpe M., (2012): circulating biomarkers with preventive, diagnostic complications in cardiovascular disease Intj cardio L ,vol(157),pp(160-168).
8. Bryant B., Knights K., (2010), Pharmacology for Health Professionals, 3rd ed, Mosby, Chats wood, NSW, Australia.

9. Centers for Disease Control and prevention (CDC), (2015): Under lying Causes of Death 2013on CDC WONDER on line Database released 2015 ,Data are from the Multiple cause of Death files 2013 ,as compiled from data provided by 57 vital statistics cooperative program, Accessed Feb, 3, 2015.

10. Christofer D., (2007): Aquasi experimental study to assess the effectiveness of structure teaching program on knowledge and skill of cardiopulmonary resuscitation among staff nurses working in selected hospitals, Degree of master of science in nursing collage of nursing.

11. Cui J., Zhou L, Lil N., (2013): Training the trainer:An educational couse for Training pain nursing specialists supported by the international Association for the study of pain (IASP), Vol (14),No(4), pp142-152).

12. Essania R., \& AliT S., (2011): Knowledge and practice gaps among pediatric nurses at tertiary care Hospital Karachia Pakistan, an open access article, volume 2011, Articlele ID 460818,P3.

13. Jarvis S, Saman S., (2017): Diagnosis, management and nursing care in acute coronary syndrome. Nursing Times [online]; ed (11), vol (3), $p p(31-35)$.

14. Jeremias M., David L., Brown M., (2010): Cardiac intensive care, path physiology of Acute coronary syndrome plaque rapture and a thermo thrombosis Saunders Elsevier, ed(2), $\mathrm{p}(73)$.

15. Manfalout's Hospital Record, (2015): Mozaffarian D., \& Benjamin E., (2015): Heart disease and stroke statistics -2015 update a report from the American Heart Association circulation,2015,ed(131),vol(29),p322.

16. Musleh B., (2015): Impact of educational program about cancer pain management on nurses at intensive care unit, master degree, critical care nursing department, faculty of nursing, Assuit University, discussion part, pp57

17. Nichols M., Townsend N., Scaborough P., Rayner M., (2014): cardiovascular disease in Europe, epidemiological update, Eur Heart 35:2950.

18. Patricia G., \& Dorrie K., (2013): Critical Care Nursing ,A Holistic Approach ,ed( $\left.10^{\text {th }}\right)$, p 207

19. Rivet S., (2012): Desensitization training CCURNS run aspirin in desensitization project at the Miriam Hospital in providence, JAM collca odiol : 1606-1610 
20. Skiner J., Nunez J., Bodi V., (2014): Influence of comorbid conditions on one-year outcomes in non-ST-segment elevation acute coronary syndrome, ed. (86), vol(4),pp:291-296.

21. Taha A., (2012): Impact of designed teaching protocol about advanced cardiac life support (ACLS) on critical care Nurses ' knowledge and practice at Benha University Hospital, Cario, Egypt, Journal of American science (2012), $\operatorname{vol}(8), \mathrm{No}(10)$. 